\title{
BOOKHAD - AN EMERGING RSLP PROJECT
}

by Sarah Mahurter

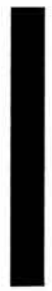

Co-operation, collaboration and interoperability meet in BOOKHAD to deliver a research resource which offers a new arrangement of key material through the use of modern technology. The essence of BOOKHAD is sharing a range of material to support scholars of book history and book design, in a focused, illustrated and subject-orientated way. The vision of the project is to provide richer access to selected resources for a community of book historians and designers than was available to them before this nationally-funded project was undertaken.

\section{Introduction}

BOOKHAD is funded by the UK's Research Support Libraries Programme (RSLP), which brings together both traditional and new forms of access to library information, with specific reference to support for research. RSLP announced the funding for BOOKHAD in July 1999. The project runs from January 2000 to December 2001.

The name 'Bookhad' came out of discussion with the partners, and means 'book history art and design', to denote the subject area of the project.

Research students within these disciplines are registered with some 20 institutions around this country; however the major book collections in these areas are held by only a few recognised institutions and by the national libraries. Although students have access to all of these collections, their location and a lack of detailed knowledge regarding specific holdings are often an impediment to their use.

BOOKHAD aims to be a seamless web interface, using the Z39.50 standard to bring together records and relevant information from six of the major holding libraries in the areas of book history and book design. It provides research support for specific humanities and social sciences collections, through retrospective conversion of the records for some of the material. It also aims to address issues of collaborative collection management, and to develop a set of guidelines which can be offered to the partner institutions.

\section{Partnership}

BOOKHAD is led by the London Institute Higher Education Corporation ${ }^{1}$, and the total of six library partners spans the higher education and public sectors. The London Institute's five collaborators are Manchester Metropolitan University, Napier Univer- sity, Reading University, St. Bride Printing Library (part of the Corporation of London) and the University of London Library at Senate House. This partnership creates a pattern of support, extending chronologically from early printed books through to modern book designers. Crossnet Systems Ltd, specialists in networked information retrieval systems, have joined the partnership to develop our ideas into 'virtual' and technical realities.

As the RSLP is one of the funding streams within higher education in the UK, a higher education (HE) body is required to lead each of the projects it finances. Alongside this requirement is the encouragement of cross-sectoral partnership. The understandable question posed by potential non-HE partners at the conception of the project was 'What will we get out of this'? As the answer could not be 'funds from RSLP', other benefits were needed to procure viable partnerships. Such benefits included establishing links with other organisations which hold major collections in similar areas; the ability to mention the project when bidding to other funding streams; opportunities to prioritise relevant work within the institution which would be of benefit to the project and also in-house. All these benefits were available to the Corporation of London, and therefore it was agreed that the St. Bride Printing Library could be a partner in this project.

\section{Resources}

The funding awarded to the project by the RSLP covered staffing, equipment and dissemination costs, and allowed a full time Project Manager to be appointed for two years. Cataloguers were contracted at the London Institute, Manchester Metropolitan University, Reading University and the University of London Library [Senate House] equivalent to one post for one year in total. Technical expertise was 
secured in the form of Crossnet Systems Ltd.

In addition to the funded resources, partnership funding was provided in the form of contributions 'in kind' from key personnel such as the special collections librarians and systems managers of each partner institution.

Two committees have been established to assist with the management of the project. These are known as the Project Contact Committee and the Project Management Committee. The first of these assists with the delivery of the aims and outcomes of the project by facilitating the involvement of the partner institutions. This Committee meets three times a year. The Project Management Committee represents senior managers of the partner institutions, acknowledged academics in the field and representatives from the research community. The role of this Committee is to provide vision and guidance to the project team, to liaise with the Project Contact Committee to ensure that the project is on target, and to act as mediator in the case of any difficulties which might occur. This Committee meets once a year.

\section{Collections}

Catalogue records from 23 collections at the six partner institutions will be available through BOOKHAD. This is a total of $c \cdot 125,000$ records, of which 16,000 will be upgraded or newly catalogued online as a result of the BOOKHAD project.

Highlights include 38,000 records from the Printing and Publishing archive at Reading University, 50,000 records of monographs and periodicals at St. Brides, 6,500 records from the book history and private press collections at Senate House, 10,000 from the book design collection at Manchester Metropolitan University, the Edward Clark collection at Napier, the Talwin Morris collection at the London College of Printing and the artists' books collection at Chelsea.

\section{Deliverables}

The project aims to sustain and greatly enhance personal access to research resources in the areas of book history and book design by delivering a web-based user interface leading to a virtual database, which will search the catalogue records described above. Links have been made to approximately 2,000 images which already exist or are being digitised as part of parallel HE-funded projects that are related to this discipline. We aim to identify a further 1,000 relevant images for future digitisation. We hope to establish guidelines which will be of use to all the partners when considering collection development and future purchases. We must ensure that the results of the project, in terms of the web interface and the virtual database, will continue to be useful and accurate as the participating collections grow in size.

\section{Technical assistance}

It was clear from the start of the BOOKHAD project that cutting edge technical skills would be required to turn this idea into a reality. To achieve that, the post of Project Technical Officer was advertised, but no suitable candidate could be identified. It was therefore agreed during the first Project Management Committee meeting that the project should approach a number of commercial companies and invite them to tender for the project. This involved establishing exactly what the project needed, in the form of a Systems Operational Requirement document. A number of experts assisted the Project Manager in writing this document, particularly from the M25 Link Consortium $^{2}$ and UKOLN ${ }^{3}$. It was necessary to consider the implications of different versions of Z39.50 at the partner sites, their current capabilities and what their staff might need to implement in order to meet the requirements of the project. The Bath Profile ${ }^{4}$ was also considered a desirable standard to bear in mind during the development of BOOKHAD. Implementation of all these standards had to be balanced against the fact that our work is using emerging technology, and that this specific use of Z39.50 has not previously been tested as far as we want to take it.

After thorough preparation a selection panel was established, which included Ronald Milne, Director of RSLP, Rachel Heery, Acting Director of UKOLN and John Gilby, Project Manager of M25 Link. Following interviews, it was decided that the proposal submitted by Crossnet Systems Ltd met our requirements.

This aspect of the project displayed collaboration, sharing and a large element of teaching and learning on the part of all those who advised and developed the specifications and participated in the selection process. The help of these experts is appreciated and acknowledged by the Project Manager.

Further work to clarify and agree terms of contract was undertaken, and a work plan commenced with Crossnet Systems Ltd in November 2000. This consisted of an initial preparation time to set up a web site, followed by a public trial early in 2001. Feedback from the trial would inform further development of the site, while a second trial in the autumn of 2001 will test the outcomes of the project. Final revisions will be made before the project ends in December 2001.

\section{The web site}

The style of the web site needs to be simple, easy to navigate and in no way an obstacle to the information it provides. The software in use makes it possible to offer a variety of search options and the use of 
Z39.50 facilitates a new organisational arrangement of specific information to support the researcher. It provides the opportunity to navigate across 23 important collections in our discipline which have not previously been linked in this way.

\section{The images}

Links have been made to 2,472 existing images, which have been digitised as part of other funded projects within the partner institutions, such as the Joint Information Systems Committee's Image Digitisation Initiative (JIDI) $)^{5}$ and the Scottish Cultural Resource Access Network (SCRAN) ${ }^{6}$. Relevant projects cover material from the Museum and Study Collection at Central Saint Martin's College of Art and Design at the London Institute and the Spellman Collection of Victorian Music Covers at Reading University. These collections form part of JIDI and will become available through the Visual Arts Data Service (VADS) web site ${ }^{7}$. Napier University and the London Institute are providing material from their catalogued collections to SCRAN, to which links are also available. Seamless access to these images has been identified as an area of improvement for the future.

There is a range of relevant material at the partner institutions which is ripe for future digitisation, and work is being carried out to identify a further 1,000 images which would be useful for researchers in book history and book design. Following the advice of the Project Management Committee a strategy has been agreed to develop a set of images on the subject of the Great Exhibition of 1851. This will act as a 'demonstrator' to which researchers or teachers could turn for themed images in support of their work. Other relevant images will also be identified to reach the target of 1,000 and information will be made available through the site.

\section{Collaborative collection management}

Collaboration to achieve collection management guidelines as a group is a current priority. Discussions on how to accomplish this have begun, and models such as those developed by similar projects and by the British Library are being examined for the benefit of BOOKHAD. For example, the Co-operative Academic Information Retrieval Network for Scotland (CAIRNS) ${ }^{8}$ has established a set of tools, which aims to assist the sharing of information regarding stock retention and withdrawal policies, collection development policies and expensive purchases. The recent publication from ARLIS/UK \& Ireland Guidelines on stock disposal ${ }^{9}$ could prove useful for the project in this area.

It is a condition of the financing of this project that outcomes will continue to be useful after the funding has ceased, and so the technical issues of how to sustain a growing database are being addressed through discussions between Crossnet Systems Ltd, VADS and the partner institutions.

\section{Progress to date}

At the time of writing, the project is in month 15 of 24. Since it was described at the ARLIS/UK \& Ireland Conference 2000, The changing agenda for art libraries, much progress has been made.

The foundations for the project, in terms of documentation and committee membership, have been established and have remained stable. The trial web site set up by Crossnet Systems Ltd has superseded the initial one, and provides details of the background to the project, the partners and collections. There are two search options, quick and advanced, and links to relevant web sites and images. A site map is being developed to aid navigation, and a feedback form is available for user comments. The trial web site has been tested by a group of volunteers and further development is planned as a result of the recommendations emanating from the trial.

The BOOKHAD discussion list ${ }^{10}$ encourages both information and resource sharing, and has provided a forum for evaluation of the test site.

Seventy-five per cent of the cataloguing is complete at Reading University, Manchester Metropolitan University, the London Institute and the University of London Library. As previously mentioned, 2,472 currently digitised images from the partner sites have been identified. This exceeds the target of 2,000 , which was promised to RSLP. Discussions continue with the Visual Arts Data Service to provide links to relevant image databases, and to host the web site once funding ceases.

All partners are making progress towards identifying and filtering records from the 23 special collections which form BOOKHAD, so that these alone are retrieved by the software and delivered to the user. The methodology being used is the insertion of a search string into the relevant records, each of which is identifiable by each of the partners through their OPACs, so that the Z39.50 software carries out a Boolean 'and' search every time a user poses a question. This way, only records from the relevant collections are retrieved, avoiding all references to, for example, 'John Smith' where he has written on the microbiology of rats! This is a breakthrough for Z39.50 searching, and proves that BOOKHAD is delivering a 'new organisational arrangement' of research resources in its subject area.

\section{Communication}

The project is building on existing knowledge in the interoperability field, such as that pioneered by col- 
leagues from the eLib ${ }^{11}$ phase 3 'clump' projects, particularly the Music On-line and M25 Link projects. All these projects aim to help researchers, and are willing to share experiences in order to achieve this goal. The BOOKHAD Project Manager is constantly looking to develop communication with projects and groups who are carrying out similar work, and would be delighted to hear from anyone else who would like to share information.

\section{Evaluation}

The first public web site of BOOKHAD underwent a four-week trial from 6th February to 2nd March 2001. The purpose of the trial was to test the look and feel, functionality and ease of use of the site and to identify any problems. Finding solutions to the identified problems will be built into the development work of the project team during the summer.

A feedback form was designed by the Project Manager to cover the site in general, the ease of the search facility, the relevance of the search results, the relevance and arrangement of the related links and images, the interest of the tester and the likelihood of future use of the site.

The trial was carried out under specific conditions: Crossnet Systems Ltd hosted the site, so that the latest version of the underlying software could be accommodated. This may have affected the speed at which testers could download the site through their browsers, particularly the images, although this was not identified as a major problem in the feedback. The ability to carry out a filtered search of the partners' OPACs was not fully in place, so the search was directed to the entire OPAC. This will not be the case in the final project outcome. As filtering was not complete, the advanced search could not be made available. Testers were asked to consider the advanced search options and comment on their usefulness. Four of the six sites had Z39.50 capability available for the trial period.

The Project Manager recruited 43 volunteer evaluators to whom the site was circulated for testing. In addition, the site was circulated to several email discussion lists and interested individuals, including bookhad@jiscmail.ac.uk, arlis-link@jiscmail.ac.uk, book-history@jiscmail.ac.uk, vads@ahds.ac.uk and sharp-1@listserv.indiana.edu.

Formal feedback forms were returned to the Project Manager, as well as comments directly via email. A small group of scholars, librarians and developers replied, with pertinent and valuable comments which were encouragingly positive. It was possible to conclude that the site is progressing well, and seems to be reaching a proportion of the scholarly community. Further work is needed to widen the awareness and use of the site.

\section{Forthcoming priorities}

The site must now be developed to a polished conclusion. Progress will continue over the summer to improve the search facilities, site map, links to images and on-screen instructions. Collaborative collection management and acquisition guidelines are in hand, and it is hoped that this outcome will be of use to a community which is wider than the BOOKHAD project team.

The project is intended to be sustained into the future, so that a growing network of illustrated resources for the study of book history and book design is established. Ways of achieving this are being discussed by the team, in liaison with national bodies.

\section{Finally ...}

A growing area such as building interoperable resources provides many opportunities for innovative development, particularly in the use of modern information and communication technology. This project aims to link across the boundaries of time and space to improve access to our rich printed heritage, for the benefit of researchers.

\section{References}

1. The London Institute Higher Education Corporation brings together in a single federated structure five of the world's most prestigious colleges for artand design-related activities. These colleges are Camberwell College of Arts, Central Saint Martin's College of Art and Design, Chelsea College of Art, the London College of Fashion and the London College of Printing.

2. A project using similar technology with a regional, rather than a subject, base.

3. United Kingdom Office for Library Networking. UKOLN is a national focus of expertise in digital information management. It provides policy, research and awareness services to the UK library, information and cultural heritage communities. UKOLN is based at the University of Bath.

4. The Bath Profile is an ISO Internationally Registered Profile (IRP) of the Z39.50 Information Retrieval Protocol, intended as a basis for effective interoperability between library and cross-domain applications. Conformance to this Profile's specifications will improve international or extra-national search and retrieval among library catalogues, union catalogues and other electronic resource discovery services worldwide.

5. The JIDI project enabled digitisation of copyright-cleared resources in 11 archival collections including resources in geology, social history and the visual arts.

6. SCRAN (http://www.scran.ac.uk) is a Millennium Commission Project to build a multimedia 


\section{BOOK AD $\begin{aligned} & \text { support for nationwide research } \\ & \text { in book history and book design }\end{aligned}$}
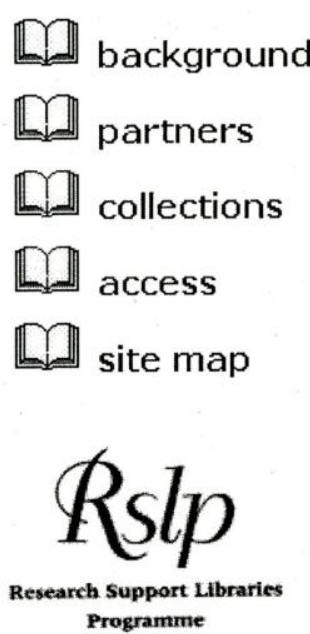

source for the study, teaching and appreciation of the history and material culture of Scotland.

7. Available at http://vads.ahds.ac.uk

8. CAIRNS aims to integrate the 25 Z39.50-compliant catalogues or information services of CAIRNS sites across Scotland into a functional and user-adaptive test-bed service.

9. ARLIS/UK \& Ireland. Guidelines on stock disposal. Bromsgrove, Worcs.: ARLIS/UK \& Ireland, 2000. 0951967452

10.bookhad@jiscmail.ac.uk

11. eLIB is managed by the JISC's Committee on

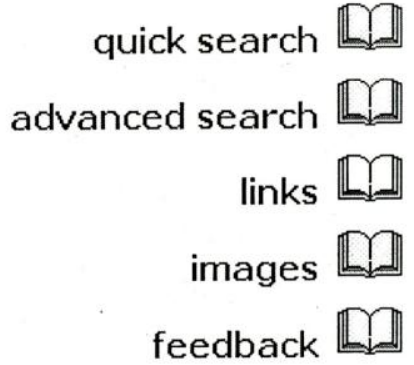

THE LONDON INSTITUTE

This page has been accessed 1487 times
Electronic Information. Its aim is to "transform the use and storage of knowledge in higher education institutions'.

Sarah Mahurter

Project Manager

RSLP - BOOKHAD

Library and Learning Resources

London College of Printing

Elephant and Castle

London, SE1 6SB

S.mahurter@lcp.linst.ac.uk

http://pugwash.crxnet.com:8080 